\title{
MERCAPTOBENZOTHIAZOLE-ON-GOLD ORGANIC PHASE BIOSENSOR SYSTEMS: 2. ENHANCED CARBAMATE PESTICIDE DETERMINATION
}

\author{
SOMERSET V. ${ }^{*}$, BAKER P. ${ }^{2}$ AND IWUOHA E. ${ }^{2}$ \\ 1NRE, CSIR, Stellenbosch, South Africa, 7600, South Africa. \\ ${ }^{2}$ SensorLab, Department of Chemistry, University of the Western Cape, Bellville, 7535, South Africa. \\ *Corresponding Author: Email- vsomerset@csir.co.za
}

\author{
Received: February 21, 2012; Accepted: April 11, 2013
}

\begin{abstract}
In this paper the results for the construction of a gold/mercaptobenzothiazole/polyaniline/ acetylcholinesterase/polyvinylacetate (Au/ MBT/PANI/AChE/PVAc) thick-film biosensor for the determination of certain carbamate pesticide solutions in selected aqueous organic solvent solutions are reported. AChE biosensors are designed to complement the classical analytical methods of pesticide detection. The Au/ MBT/PANI/AChE/PVAc electrocatalytic biosensor device was constructed by encapsulating acetylcholinesterase (AChE) enzyme in the PANI polymer composite, followed by the coating of poly(vinyl acetate) (PVAc) on top to secure the biosensor film from disintegration in the organic solvents evaluated. The electroactive substrate called acetylthiocholine (ATCh) was employed to provide the movement of electrons in the amperometric biosensor. The voltammetric results have shown that the current shifts more anodically as the Au/MBT/PANI/AChE/PVAc biosensor responded to successive acetylthiocholine (ATCh) substrate addition under anaerobic conditions in $0.1 \mathrm{M}$ phosphate buffer, $\mathrm{KCl}(\mathrm{pH}$ 7.2) solution and aqueous organic solvent solutions. For the Au/MBT/PANI/AChE/PVAc biosensor, various performance and stability parameters were evaluated. These factors include the optimal enzyme loading, effect of $\mathrm{pH}$, long-term stability of the biosensor, temperature stability of the biosensor, the effect of polar organic solvents, and the effect of non-polar organic solvents on the amperometric behavior of the biosensor. The biosensor constructed in this study offered a reasonable linear range between 0.25 to $3.45 \mathrm{nM}$ for the detection of carbofuran, aldicarb and dioxacarb pesticide solutions. The detection limits for the individual carbamate pesticides were $0.249 \mathrm{nM}$ for carbofuran, followed by $1.209 \mathrm{nM}$ for aldicarb and $1.572 \mathrm{nM}$ for dioxacarb.
\end{abstract}

Keywords- Organic phase biosensor, acetylcholinesterase, carbamate pesticides, carbofuran, aldicarb, dioxacarb

Citation: Somerset V., Baker P. and Iwuoha E. (2013) Mercaptobenzothiazole-On-Gold Organic Phase Biosensor Systems: 2. Enhanced Carbamate Pesticide Determination. International Journal of Chemical Research, ISSN: 0975-3699 \& E-ISSN: 0975-9131, Volume 5, Issue 1, pp.$144-152$.

Copyright: Copyright@2013 Somerset V., et al. This is an open-access article distributed under the terms of the Creative Commons Attribution License, which permits unrestricted use, distribution and reproduction in any medium, provided the original author and source are credited.

\section{Introduction}

The use of pesticides in the agricultural industry is still widespread as it is seen to increase the yield of crops, despite the negative impacts it may have on the environment and human health. Pesticides can be divided into insecticides (26\%), fungicides (31\%) and herbicides (43\%), with several sub-classes belonging to these main categories. The last two decades have also seen an increasing growth in the routine application of organophosphorous (OP) and carbamate (CM) pesticides in the agricultural community. This has lead to increasing concerns with respect to the disastrous effects on the environment and also on human, animal and insect health [1-3]. Organophosphate (OP) and carbamates (CM) pesticides inhibit the activity of the enzyme called acetylcholinesterase (AChE) in vertebrates and insects. AChE is required in the hydrolysis of the neurotransmitter acetylcholine, which in turn is responsible for the transmission of nervous impulses. Any inhibition of the activity of AChE leads to an increase in acetylcholine in the synapses, which in turn disrupts neurotransmission. Symptoms of acute toxicity include increased salivation, headaches, convulsions and suppressed breathing that can lead to death [1-6].

The determination of organophosphate (OP) and carbamate (CM) pesticides in various samples has therefore become increasing importantly, due to the widespread use of these compounds. The standard methods that have been widely used for the determination of OP and CM compounds include gas chromatography (GC), high performance liquid chromatography (HPLC) and HPLC coupled with mass spectrometry (HPLC-MS) or UV detection (HPLC-UV) [3,710]. However, alternative and/or complementary methods such as the use of biosensors have been reported over the last decade. In order to determine trace levels of pesticide compounds rapidly and reliably, various biosensor systems operating on the inhibition and non-inhibition principle have been developed. The enzymes used in the construction of these biosensors include acetylcholinesterase (AChE), cholinesterase (ChE) or organophosphorus hydrolase (OPH) $[11,12]$.

Biosensors containing the enzymes AChE and ChE normally operate on the inhibition principle in which case the procedures involve the measurement of the uninhibited activity of the enzyme, followed 
by an incubation period for the reaction between enzyme and inhibitor and the measurement of the enzyme activity after the inhibition $[3,13]$. On the other hand, OPH-based biosensors operate on the non-inhibition route and provide a direct biosensing route, but due to $\mathrm{OPH}$ not being commercially available, the widespread use of these biosensors is very limited. Therefore, biosensors for the detection of OP and CM pesticides that operate on the inhibition principle have been widely developed [11,13-15]. Furthermore, the choice of enzyme in the construction of a biosensor for pesticide detection is not the only parameter to consider, since the type of transducer (electrochemical, optical or piezoelectric) and modification of its surface is another important parameter $[11,13]$.

Only few publications address the detection of pesticides in nonaqueous environments, especially those in which AChE biosensors have been applied for carbamate detection. Carbamate and organophosphorus pesticides are characterized by a low solubility in water and a higher solubility in organic solvents. For this reason, the extraction and concentration of pesticides from fruits, vegetables and other matrices are carried out in organic solvents. Furthermore, some enzymes work well in both water and organic solvents, but other enzymes require a minimum amount of water to retain catalytic activity. The detection of carbamate pesticides reported in this study investigated the effect of hydration on the functioning of the enzyme during biosensor detection $[3,16]$.

In a previous paper, the application of a mercaptobenzothiazole-ongold biosensor system for application to organophosphorous pesticide determination has been reported. This paper further report the results obtained for the biosensor analysis of the carbamate pesticides called dioxacarb, aldicarb and carbofuran. The results reported in this study, describe the application of a mercaptobenzothiazole-on-gold biosensor system for carbamate pesticide determination. The aim of this work was to improve the detection limit of carbamate insecticides with an AChE biosensor, applied to various water miscible organic solvents. The activity of the AChE immobilized in the biosensor construction was measured by amperometry based on the detection of thiocholine produced in the enzymatic hydrolysis of acetylthiocholine as substrate. The application biosensor to various carbamate pesticide compounds was further performed in aqueous organic media to ascertain the role of organic phase on the reactivity of the enzyme and the performance of the biosensor.

\section{Materials and Methods \\ Reagents and Materials}

The reagents aniline (99\%), potassium dihydrogen phosphate $(99+\%)$, disodium hydrogen phosphate $(98+\%)$ and diethyl ether $(99.9 \%)$ were obtained from Aldrich, Germany. The acetylthiocholine chloride (99\%) and poly(vinyl acetate) (PVAc) was obtained from Sigma, Germany. The mercaptobenzothiazole (MBT), acetylcholinesterase (AChE, from Electrophorus electricus, EC 3.1.1.7; $850 \mathrm{U} / \mathrm{mg})$, acetylcholine chloride (99\%) and acetone (>99.8\%, pestanal) were obtained from Fluka, Germany. The hydrogen peroxide (30\%) and the organic solvents ethanol $(99.9 \%$, absolute grade), acetonitrile $(99.9 \%$, pestanal grade) were purchased from Riedel-de Haën, Germany. The potassium chloride, sulphuric acid $(95 \%)$, and hydrochloric acid (32\%) were obtained from Merck, South Africa. Carbamate pesticides used in this study include dioxacarb, aldicarb and carbofuran. These pesticide standards were purchased from Riedel-de Haën, Germany.
Platinum (Pt) wires as counter electrodes were obtained from Sigma-Aldrich, South Africa. Alumina micropolish and polishing pads that were used for the polishing of the working electrode were obtained from Buehler, IL, USA [3,17].

\section{Instrumentation}

All electrochemical protocols were performed and recorded with a computer interfaced to a BAS-50/W electrochemical analyser with BAS-50/W software (Bioanalytical Systems, Lafayette, IN, USA), using either cyclic voltammetry (CV), Oysteryoung square wave voltammetry (OSWV), differential pulse voltammetry (DPV) or timebased amperometric modes. A conventional three electrode system was employed. The working electrode was a gold disc electrode (diameter: $1.6 \mathrm{~mm}$; area: $2.01 \times 10^{-2} \mathrm{~cm}^{2}$; Bioanalytical Systems, Lafayette, IN, USA). Silver/silver chloride ( $\mathrm{Ag} / \mathrm{AgCl}-3 \mathrm{M} \mathrm{NaCl}$ type) was used as the reference electrode and a platinum wire was used as auxiliary electrode $[3,18]$.

\section{Electrode Surface Preparation and Bio-electrode Construction}

Prior to use, gold electrodes were first polished on aqueous slurries of $1 \mathrm{~mm}, 0.3 \mathrm{~mm}$ and $0.05 \mathrm{~mm}$ alumina powder. After thorough rinsing in deionised water followed by acetone, the electrodes were etched for about 5 minutes in a hot 'Piranha' solution $\{1: 3(\mathrm{v} / \mathrm{v}) 30 \%$ $\mathrm{H}_{2} \mathrm{O}_{2}$ and concentrated $\left.\mathrm{H}_{2} \mathrm{SO}_{4}\right\}$ and rinsed again with copious amounts of deionised water. The polished electrodes were then cleaned electrochemically by cycling the potential scan between 200 and $+1500 \mathrm{mV}$ (vs. $\mathrm{Ag} / \mathrm{AgCl}$ ) in $0.05 \mathrm{M} \mathrm{H}_{2} \mathrm{SO}_{4}$ at the scan rate of $40 \mathrm{mV} / \mathrm{s}$ for 10 min or until the CV characteristics for a clean $\mathrm{Au}$ electrode were obtained.

The platinum (Pt) counter electrode was regularly cleaned before and after synthesis and in between synthesis and analysis. This involved flaming the Pt electrode in a Bunsen burner until it was white hot, followed by rinsing with copious quantities of deionised water [3,19-20].

A self-assembled monolayer (SAM) of mercaptobenzothiazole (MBT) was formed by immersing the cleaned Au electrode into an ethanol solution containing $10 \mathrm{mM}$ of MBT for 2 hours. After deposition the SAM electrode was rinsed extensively with ethanol and water and kept in $0.1 \mathrm{M}$ phosphate buffer ( $\mathrm{pH} \mathrm{7.2)}$ for later use. This electrode was then referred to as Au/MBT [21].

The next step involved the electropolymerisation of the polymer film. A three electrode arrangement was set up in a sealed $10 \mathrm{ml}$ electrochemical cell. Polyaniline (PANI) films were prepared by electropolymerisation from a $0.2 \mathrm{M}$ aniline solution dissolved in $1 \mathrm{M}$ hydrochloric acid $(\mathrm{HCl})$ onto the previously prepared Au/MBTmodified electrode. The aniline/ $\mathrm{HCl}$ solution was first degassed by passing argon ( $\mathrm{Ar})$ through the solution for approximately ten minutes and keeping the Ar blanket during electropolymerisation. Initial optimisation of the potential window for electropolymerisation was performed. During electropolymerisation the potential was scanned from an initial potential $\left(E_{i}\right)$ of $-200 \mathrm{mV}$ to a switch potential $\left(E_{\lambda}\right)$ of $+1200 \mathrm{mV}$, at a scan rate of $40 \mathrm{mV} / \mathrm{s}$ vs. $\mathrm{Ag} / \mathrm{AgCl}$ as a reference. The polymerisation process was stopped after 10 voltammetric cycles, to ensure a smooth and relatively thin polymer film surface was obtained. The Au/MBT-polyaniline modified electrode was then rinsed with deionised water and used as the working electrode in subsequent studies. The electrode will be referred to as Au/MBT/ PANI for the gold-MBT-PANI modified electrode [22-24]. 


\section{Preparation of Thick-film Enzyme Electrode}

Following the electropolymerisation of a fresh PANI polymer film on an Au/MBT electrode, the Au/MBT/PANI electrode was transferred to a batch cell, containing $1 \mathrm{ml}$ argon degassed $0.1 \mathrm{M}$ phosphate buffer ( $\mathrm{pH}$ 7.2) solution. The PANI polymer film was then reduced at a potential of $-500 \mathrm{mV}$ (vs. $\mathrm{Ag} / \mathrm{AgCl}$ ) until a steady current was achieved, which took approximately thirty minutes.

Electrochemical incorporation of the enzyme acetylcholinesterase (AChE) onto the PANI film was carried out next. This involved the addition of $60 \mu \mathrm{L}$ of $A C h E$ to the $0.1 \mathrm{M}$ phosphate buffer ( $\mathrm{pH} 7.2$ ) solution. After the enzyme solution was argon degassed, enzyme immobilisation was achieved by oxidation of the PANI film in the presence of $\mathrm{AChE}$ at a potential of $+400 \mathrm{mV}$ (vs. $\mathrm{Ag} / \mathrm{AgCl}$ ) until a steady current was achieved, which took approximately fourty minutes.

During the oxidation step, the enzyme AChE was electrostatically attached to the polymer film via an ion-exchange process. The biosensor was then rinsed with deionised water to remove any unbound enzyme and stored in the working $0.1 \mathrm{M}$ phosphate buffer (pH 7.2) solution at $4^{\circ} \mathrm{C}$. The resulting thick-film enzyme electrode will be referred to as Au/MBT/PANI/AChE biosensor.

For the Au/MBT/PANI/AChE bioelectrode, after enzyme incorporation it was arranged vertically and then coated with a $2 \mu \mathrm{L}$ drop of poly (vinyl acetate) (PVAc) solution ( $0.3 \mathrm{M}$ ) prepared in acetone and left to dry for $1 \mathrm{~min}$. This resulting thick-film biosensor will be referred to as Au/MBT/PANI/AChE/PVAc biosensor [29].

\section{Electrochemical Evaluation of AChE-based Biosensors using Acetylthiocholine}

The electrochemical cell used for the electrocatalytic oxidation of acetylthiocholine (ATCh) consisted of Au/MBT/PANI/AChE/PVAc bioelectrode, platinum wire and $\mathrm{Ag} / \mathrm{AgCl}$ as the working, counter and reference electrode, respectively. A $1 \mathrm{ml}$ test solution containing $0.1 \mathrm{M}$ phosphate $(0.1 \mathrm{M} \mathrm{KCl}, \mathrm{pH} 7.2)$ solution was degassed with argon before any substrate was added and after each addition of small aliquots of $0.01 \mathrm{M}$ acetylthiocholine (ATCh). Cyclic, square wave and differential pulse voltammetry were used to measure the responses of the AChE-based biosensor towards ATCh as substrate.

Cyclic voltammetry (CV) was performed at a slow scan rate of 10 $\mathrm{mV} / \mathrm{s}$ to study the catalytic oxidation of ATCh by applying a linear potential scan between $-400 \mathrm{mV}$ and $+1800 \mathrm{mV}$ (vs. $\mathrm{Ag} / \mathrm{AgCl})$. The cyclic voltammogram was first obtained in the absence of the substrate ATCh, followed by analysis in the presence of ATCh as substrate. Sequential $20 \mathrm{ml}$ aliquots of $0.01 \mathrm{M}$ acetylthiocholine (ATCh) were then added to the $1 \mathrm{ml}$ of $0.1 \mathrm{M}$ phosphate buffer $(0.1 \mathrm{M} \mathrm{KCl}$, $\mathrm{pH}$ 7.2) solution, degassed with argon and a blanket of gas was kept for the duration of the experiment. The phosphate buffer solution was stirred after each addition of ATCh. This was done to ensure homogeneity of the solution before measurements were taken.

Osteryoung-type square wave voltammetry (OSWV) was performed immediately after cyclic voltammetric analysis with the AChE-based biosensor in $1 \mathrm{ml}$ of $0.1 \mathrm{M}$ phosphate buffer $(0.1 \mathrm{M} \mathrm{KCl}, \mathrm{pH} 7.2)$ solution, containing different concentrations of ATCh as the substrate under anaerobic conditions (system kept under an argon blanket). The anodic difference square wave voltammogram (SWV) was collected in an oxidation direction only by applying a linear potential scan between $-400 \mathrm{mV}$ and $+1800 \mathrm{mV}$ (vs. $\mathrm{Ag} / \mathrm{AgCl}$ ), at a step potential of $4 \mathrm{mV}$, a frequency of $5 \mathrm{~Hz}$, and a square wave amplitude of $50 \mathrm{mV}$. The SWV was first obtained in the absence of the substrate ATCh, followed by analysis in the presence of ATCh as substrate.

Differential pulse voltammetry (DPV) immediately followed SWV analysis with the AChE-based biosensor in $1 \mathrm{ml}$ of $0.1 \mathrm{M}$ phosphate buffer $(0.1 \mathrm{M} \mathrm{KCl}, \mathrm{pH} 7.2)$ solution, containing different concentrations of ATCh as the substrate under anaerobic conditions (system kept under an argon blanket). The anodic difference differential pulse voltammogram (DPV) was collected in an oxidation direction only by applying a linear potential scan between $-400 \mathrm{mV}$ and + $1800 \mathrm{mV}$ (vs. $\mathrm{Ag} / \mathrm{AgCl}$ ), at a scan rate of $10 \mathrm{mV} . \mathrm{s}^{-1}$ and a pulse amplitude of $50 \mathrm{mV}$. The sample width, pulse width and pulse period were $17 \mathrm{~ms}, 50 \mathrm{~ms}$ and $200 \mathrm{~ms}$, respectively. The DPV was first obtained in the absence of the substrate ATCh, followed by analysis in the presence of ATCh as substrate [25-29].

\section{Inhibition Studies in the Presence of Pesticide Inhibitors}

A new Au/MBT/PANI/AChE/PVAc biosensor was prepared each time a new carbamate pesticide was studied. A new biosensor was also prepared for each of the six concentrations of the carbamate pesticides studied. The electrochemical cell consisted of Au/MBT/ $\mathrm{PANI} / \mathrm{AChE} / \mathrm{PVAc}$ bioelectrode, platinum wire and $\mathrm{Ag} / \mathrm{AgCl}$ as the working, counter and reference electrode, respectively. A $1 \mathrm{ml}$ test solution containing $0.1 \mathrm{M}$ phosphate $(0.1 \mathrm{M} \mathrm{KCl}, \mathrm{pH} 7.2)$ solution was degassed with argon before any substrate was added and after each addition of small aliquots of $0.01 \mathrm{M}$ acetylthiocholine (ATCh).

Inhibition plots for each of the carbamate pesticides detected were obtained using the percentage inhibition method. The following procedure was used. The biosensor was first placed in a stirred 1 $\mathrm{ml}$ of $0.1 \mathrm{M}$ phosphate $(0.1 \mathrm{M} \mathrm{KCl}, \mathrm{pH} 7.2$ ) solution (anaerobic conditions) and multiple additions of a standard acetylthiocholine (ATCh) substrate solution was added until a stable current and a maximum concentration of $2.4 \mathrm{mM}$ were obtained. This steady state current is related to the activity of the enzyme in the biosensor when no inhibitor was present. This was followed by incubating the biosensor in anaerobic conditions for 20 min with a standard pesticide phosphate buffer-organic solvent mixture. This was followed by multiple additions of a standard ATCh substrate solution (anaerobic conditions), to a fresh $1 \mathrm{ml}$ of $0.1 \mathrm{M}$ phosphate $(0.1 \mathrm{M} \mathrm{KCl}, \mathrm{pH} 7.2)$ solution (anaerobic conditions) and multiple additions of a standard acetylthiocholine (ATCh) substrate solution was again added, until a stable current was obtained. The maximum concentration of acetylthiocholine (ATCh) was again $2.4 \mathrm{mM}$. The percentage inhibition was then calculated using the formula [30-33]:

$$
I \%=\frac{\left(I_{1}-I_{2}\right)}{I_{1}} \times 100
$$

where $1 \%$ is the degree of inhibition, $I_{1}$ is the steady-state current obtained in buffer solution, $I_{2}$ is the steady-state current obtained after the biosensor was incubated for $20 \mathrm{~min}$ in phosphate bufferorganic solvent mixture. Cyclic, square wave and differential pulse voltammetric measurements were performed after each addition of ATCh up to a maximum concentration of $2.4 \mathrm{mM}$. Cyclic voltammetry (CV) was performed at a scan rate of $10 \mathrm{mV} . \mathrm{s}^{-1}$ by applying a linear potential scan between $-400 \mathrm{mV}$ and $+1800 \mathrm{mV}$ (vs. Ag/ $\mathrm{AgCl})$. For some experimental runs the anodic difference square wave voltammogram (SWV) was collected in an oxidation direction only by applying a linear potential scan between $-400 \mathrm{mV}$ and + $1800 \mathrm{mV}$ (vs. $\mathrm{Ag} / \mathrm{AgCl}$ ), at a step potential of $4 \mathrm{mV}$, a frequency of 5 $\mathrm{Hz}$, and a square amplitude of $50 \mathrm{mV}$. 
The anodic difference differential pulse voltammogram (DPV) was collected in an oxidation direction only by applying a linear potential scan between $-400 \mathrm{mV}$ and $+1800 \mathrm{mV}$ (vs. $\mathrm{Ag} / \mathrm{AgCl})$, at a scan rate of $10 \mathrm{mV} . \mathrm{s}^{-1}$ and a pulse amplitude of $50 \mathrm{mV}$. The sample width, pulse width and pulse period were $17 \mathrm{~ms}, 50 \mathrm{~ms}$ and $200 \mathrm{~ms}$, respectively [29].

\section{Optimisation of Acetylcholinesterase (AChE) Enzyme Loading}

The operation of the Au/MBT/PANI/AChE/PVAc biosensor was evaluated at different amounts of AChE enzyme incorporated into the biosensor. To achieve this, $0.1 \mathrm{M}$ phosphate buffer, $0.1 \mathrm{M} \mathrm{KCl}$ (pH 7.2) solutions were prepared and used. Following the electropolymerisation of a fresh PANI polymer film on an Au/MBT electrode, the Au/MBT/PANI electrode was transferred to a batch cell, containing $1 \mathrm{ml}$ argon degassed $0.1 \mathrm{M}$ phosphate buffer ( $\mathrm{pH} 7.2$ ) solution. The PANI polymer film was then reduced at a potential of $500 \mathrm{mV}$ (vs. Ag/AgCl) until a steady current was achieved, which took approximately thirty minutes.

Electrochemical incorporation of the enzyme acetylcholinesterase (AChE) onto the PANI film was carried out next. This involved the addition of $40 \mu \mathrm{L}$ of AChE to the $0.1 \mathrm{M}$ phosphate buffer $(\mathrm{pH} 7.2)$ solution. After the enzyme solution was argon degassed, enzyme immobilisation was achieved by oxidation of the PANI film in the presence of $\mathrm{AChE}$ at a potential of $+400 \mathrm{mV}$ (vs. $\mathrm{Ag} / \mathrm{AgCl}$ ) until a steady current was achieved, which took approximately fourty minutes. The Au/MBT/PANI bioelectrode was arranged vertically and then coated with a $2 \mu \mathrm{L}$ drop of poly(vinyl acetate) (PVAc) solution $(0.3 \mathrm{M})$ prepared in acetone and left to dry for $1 \mathrm{~min}$.. The same procedure was followed to incorporate 60 and $80 \mu \mathrm{L}$ of AChE enzyme into the PANI polymer surface.

Voltammetric characterisation was performed at a slow scan rate of $10 \mathrm{mV}^{-1} \mathrm{~s}^{-1}$ to study the catalytic oxidation of ATCh by applying a linear potential scan between $-400 \mathrm{mV}$ and $+1800 \mathrm{mV}$ (vs. Ag/ $\mathrm{AgCl})$. The voltammograms were first obtained in the absence of the substrate ATCh, followed by analysis in the presence of ATCh as substrate. Sequential $20 \mathrm{ml}$ aliquots of $0.01 \mathrm{M}$ acetylthiocholine (ATCh) were then added to the $1 \mathrm{ml}$ of $0.1 \mathrm{M}$ phosphate buffer $(0.1$ $\mathrm{M} \mathrm{KCl}, \mathrm{pH}$ 7.2) solution, degassed with argon and a blanket of gas was kept for the duration of the experiment. The phosphate buffer solution was stirred after each addition of ATCh. This was done to ensure homogeneity of the solution before measurements were taken $[29,34]$.

\section{pH Influence and Optimisation Studies}

The operation of the Au/MBT/PANI/AChE/PVAc biosensor was evaluated at different $\mathrm{pH}$ values. To achieve this, $0.1 \mathrm{M}$ phosphate buffer, $0.1 \mathrm{M} \mathrm{KCl}$ solutions were prepared at different $\mathrm{pH}$ values of $6.0 ; 6.5 ; 7.2 ; 7.5$ and 8.0 . A $1 \mathrm{ml}$ test solution containing $0.1 \mathrm{M}$ phosphate buffer, $0.1 \mathrm{M} \mathrm{KCl}$ solution was degassed with argon before any substrate was added. The Au/MBT/PANI/AChE/PVAc biosensor was then evaluated in the $1 \mathrm{ml}$ test solution with small aliquots of the substrate consisting of $0.01 \mathrm{M}$ acetylthiocholine (ATCh) being added to the test solution, followed by degassing. The maximum current response of the biosensor was then obtained at the different $\mathrm{pH}$ values after $2 \mathrm{mM}$ of the ATCh substrate was added to the Au/MBT/PANI/AChE/PVAc biosensor [29].

\section{Temperature and Stability Studies}

The temperature stability of the Au/MBT/PANI/AChE/PVAc biosensor was evaluated at different temperature values. To achieve this, the optimum temperature for AChE activity in the constructed biosensor was determined by assaying the biosensor at various temperatures of $10,15,20,25,30$, and $35^{\circ} \mathrm{C}$.

A $1 \mathrm{ml}$ test solution containing $0.1 \mathrm{M}$ phosphate buffer, $0.1 \mathrm{M} \mathrm{KCl}$ solution was degassed with argon before any substrate was added, and incubated in a small water bath for approximately 10 minutes at a specific temperature. The Au/MBT/PANI/AChE/PVAc biosensor was then evaluated in the $1 \mathrm{ml}$ test solution with small aliquots of the substrate consisting of $0.01 \mathrm{M}$ acetylthiocholine (ATCh) being added to the test solution, followed by degassing. The maximum current response of the biosensor was then obtained after $2 \mathrm{mM}$ of the ATCh substrate was added to the Au/MBT/PANI/AChE/PVAc biosensor. This procedure was performed at 10, 15, 20, 25, 30, and $35^{\circ} \mathrm{C}$ using different Au/MBT/PANI/AChE/PVAc biosensors [29,3536]

The operation of the Au/MBT/PANI/AChE/PVAc biosensor was evaluated at different time intervals of 7 day periods for a total of 30 days, using one specific biosensor. A $1 \mathrm{ml}$ test solution containing $0.1 \mathrm{M}$ phosphate buffer, $0.1 \mathrm{M} \mathrm{KCl}$ solution was degassed with argon before any substrate was added. The Au/MBT/PANI/AChE/ PVAc biosensor was then evaluated in the $1 \mathrm{ml}$ test solution with small aliquots of the substrate consisting of $0.01 \mathrm{M}$ acetylthiocholine (ATCh) being added to the test solution, followed by degassing. The maximum current response of the biosensor was then obtained after $2 \mathrm{mM}$ of the ATCh substrate was added to the Au/MBT/PANI/ AChE/PVAc biosensor. This procedure was performed on $0,7,14$, 21 and 28 days using one specific Au/MBT/PANI/AChE/PVAc biosensor [29].

\section{Determination of the Limit of Detection (LOD)}

A $1 \mathrm{ml}$ test solution containing $0.1 \mathrm{M}$ phosphate buffer, $0.1 \mathrm{M} \mathrm{KCl}$ solution was degassed with argon before any substrate was added. The AChE-biosensor was then evaluated in the $1 \mathrm{ml}$ test solution by performing 10 replicate measurements on the $0.1 \mathrm{M}$ phosphate buffer, $0.1 \mathrm{M} \mathrm{KCl}$ solution, or on any one of the analyte (standard pesticide) solutions at the lowest working concentration. A calibration graph of current $(A)$ versus saline phosphate buffer or analyte concentration was then constructed for which the slope and the linear range was then determined. The limit of detection (LOD) was then calculated with the following equation [Eq-2]:

$$
L O D=\frac{3 \cdot \sigma_{n-1}}{m}=\frac{3 \cdot s}{m}
$$

where $s$ is the standard deviation of the 10 replicate measurements on the $0.1 \mathrm{M}$ phosphate buffer, $0.1 \mathrm{M} \mathrm{KCl}$ solution, or on any one of the analyte (standard pesticide) solutions at the lowest working concentration. The variable $m$ represents the slope of the calibration graph in the linear range that is also equal to the sensitivity of the measurements performed [29]

\section{Organic Solvent Studies}

The response of the Au/MBT/PANI/AChE/PVAc biosensor was evaluated before and after exposure to polar organic solvents, in order to determine the response of the AChE enzyme to acetonitrile, acetone and ethanol as solvents. The sensor response was first measured in a $0.1 \mathrm{M}$ phosphate buffer, $\mathrm{KCl}(\mathrm{pH} \mathrm{7.2)} \mathrm{solution,} \mathrm{in}$ the presence of a fixed concentration of ATCh. This was followed by incubating the biosensor for 20 minutes in an aqueous-solvent mixture or the pure organic solvent. The Au/MBT/PANI/AChE/PVAc biosensor response was then again measured in a $0.1 \mathrm{M}$ phosphate 
buffer, $\mathrm{KCl}(\mathrm{pH} 7.2)$ solution, in the presence of a fixed concentration of ATCh to determine any inhibitory effects. The percentage inhibition $(\% /)$ response was then calculated as outlined in section 2.6 and reported [29].

\section{Results and Discussion}

\section{Thick-film Biosensor Design}

This work demonstrates that a gold disc electrode can be coated with a mercaptobenzothiazole (MBT) self-assembled monolayer (SAM) prior to polyaniline electropolymerisation, followed by AChE immobilisation and poly(vinyl acetate) coating in creating a thick film electrode for sensitive organophosphorous pesticide detection. The dual role of polyaniline, which shows electrocatalytic activity towards thiocholine and serves as an immobilisation matrix for the AChE as an enzyme and that of poly(vinyl acetate) (PVAc) as a binder in this thick-film electrode is demonstrated. Polyaniline (PANI) was used as a mediator in this biosensor construction to harvest its dual role as immobilisation matrix for AChE and use its electrocatalytic activity towards thiocholine (TCh) for amperometric sensing. With that in mind, the following amperometric sensor design and mechanism is proposed and explained, showed in [Fig-1] [29].

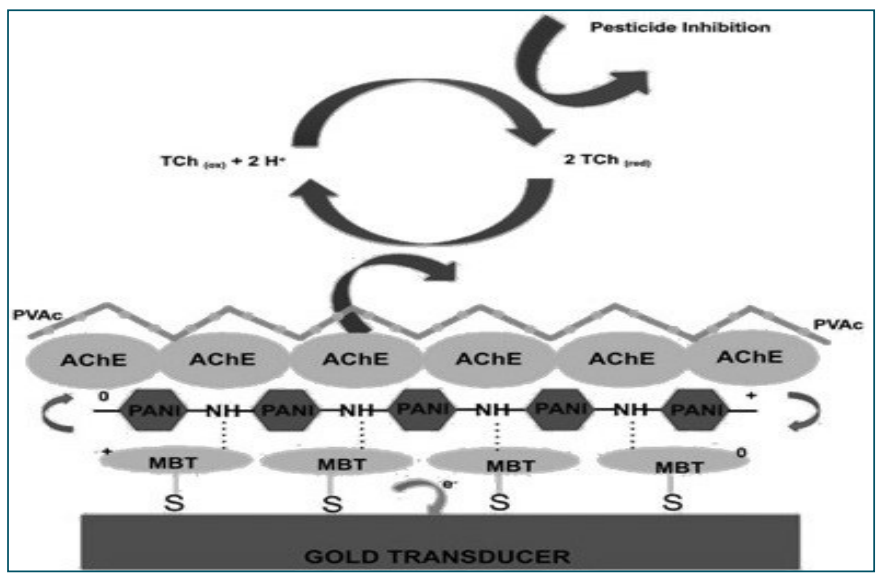

Fig. 1- Schematic diagram representing the functioning and electron shutteling in the Au/MBT/PANI/AChE/PVAc thick-film biosensor in the presence of thiocholine and inhibition by carbamate pesticides

In [Fig-1] the schematic representation for the biosensor reaction taking place is presented. In this figure it is depicted that as acetylthiocholine (ATCh) is catalysed by acetylcholinesterase (AChE), it forms thiocholine (TCh) and acetic acid (not shown). Thiocholine is electroactive and is oxidised in the reaction. With the enzyme AChE embedded in PANI, the conducting polymer interacts with thiocholine and also accepts an electron from mercaptobenzothiazole as it is oxidised through interaction with the gold electrode. In this manner a constant shutteling of electrons in the biosensor set-up is achieved [29].

\section{Electrochemical Evaluation of thick-film Biosensor}

In [Fig-2] the results for the differential pulse voltammetric (DPV) evaluation of the constructed biosensor is shown. The DPV responses for the Au/MBT/PANI/AChE/PVAc biosensor was monitored for the successive addition of ATCh substrate and the electrocatalytic response of the biosensor showed an increasing anodic current response with increasing substrate addition as illustrated by the DPV results shown in [Fig-2].

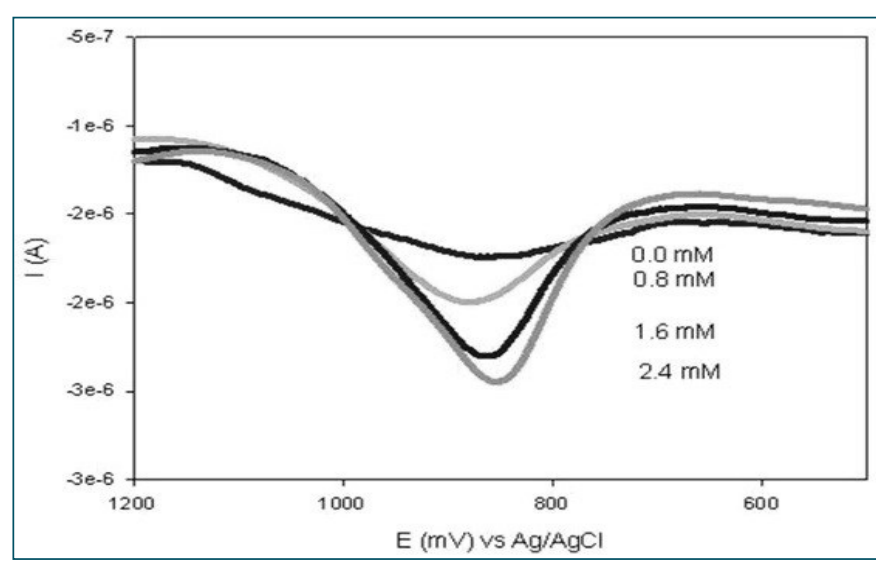

Fig. 2- DPV response of successive ATCh substrate addition to Au/ MBT/PANI/AChE/PVAc biosensor in $0.1 \mathrm{M}$ phosphate buffer, $\mathrm{KCl}$ $(\mathrm{pH} 7.2)$ solution at a scan rate of $10 \mathrm{mV} . \mathrm{s}-1$, and in a potential window of +500 to $+1200 \mathrm{mV}$

The DPV results in [Fig-2] are shown in a shorter potential window to highlight the observed increase in anodic peak current. The results show the voltammetric responses for the electrocatalytic oxidation of acetylthiocholine at the Au/MBT/PANI/AChE/PVAc biosensor. The DPV responses shows an increase in peak current heights upon the successive additions of ATCh as substrate, with the results more pronounced around a specific potential of $861.5 \mathrm{mV}$ (vs. $\mathrm{Ag} / \mathrm{AgCl}$ ). These results clearly indicated that a biosensor was established and that AChE as enzyme was hydrolysing the substrate ATCh, with the increase in oxidative current as the preferred route of reaction [29].

\section{Optimisation of Acetylcholinesterase (AChE) Enzyme Loading}

The amount of enzyme incorporated during the biosensor construction is an important element during construction and it affects the sensor's limit of detection. If the aim of the biosensor is to achieve the lowest possible detection, only a minimum amount of enzyme must be used [26,37-38].

Since the enzyme AChE was incorporated into the PANI polymer matrix by adsorption at fixed potential, different amounts of the enzyme was dissolved in a $1 \mathrm{ml}$ of $0.1 \mathrm{M}$ phosphate buffer $(\mathrm{pH} 7.2)$ solution. In [Table-1] the results obtained for the optimisation of the enzyme loading is displayed.

Table 1- The results for the amperometric response of the AChE biosensor to different amounts of enzyme incorporated into the biosensor construction. These responses were measured in a $0.1 \mathrm{M}$ phosphate buffer, $\mathrm{KCl}(\mathrm{pH} 7.2)$ solution at $25^{\circ} \mathrm{C}(n=2)$

\begin{tabular}{cc|}
$\begin{array}{c}\text { Enzyme Optimization Results } \\
\text { Amount of enzyme } \\
\text { ( } \mu \mathrm{L} / 1 \mathrm{~mL} \text { of buffer solution) }\end{array}$ & Anodic peak current response, $\mathrm{I}_{\mathrm{p}, \mathrm{a}}(\mathrm{A})$ \\
\hline 40 & $1.3 \times 10^{-6}$ \\
50 & $3.2 \times 10^{-6}$ \\
60 & $5.7 \times 10^{-6}$ \\
80 & $5.1 \times 10^{-6}$ \\
\hline
\end{tabular}

From the results in [Table-1] it can be seen that the highest anodic current response for the addition of ATCh substrate to the biosensor, was experienced when the biosensor had $60 \mu \mathrm{L}$ of AChE dissolved in $1 \mathrm{ml}$ of $0.1 \mathrm{M}$ phosphate buffer ( $\mathrm{pH} \mathrm{7.2)} \mathrm{solution.} \mathrm{The}$ results obtained when $80 \mu \mathrm{L}$ of AChE was used, does not show a very big difference in the current response when compared to the use of $60 \mu \mathrm{L}$ of AChE. In both these cases it was observed that the 
biosensor response to ATCh substrate addition starts to level off after $1.0 \mathrm{mM}$ of the substrate has been added (graph not shown here). When the results for the use of 60 and $80 \mu \mathrm{L}$ of AChE is compared to that of the 40 and $50 \mu \mathrm{L}$ of $\mathrm{AChE}$, a big difference in the amperometric response was observed, with the current increasing in several magnitudes. When a small amount of enzyme is incorporated into the biosensor, a very small response in anodic current was thus observed. Therefore, optimal enzyme loading was maintained at $60 \mu \mathrm{L}$ for all biosensor experiments reported in this study [29].

\section{Influence of pH on Thick-film Biosensor}

The $\mathrm{pH}$ value of the working solution is usually regarded as the most important factor in determining the performance of a biosensor and its sensitivity towards inhibitors. It is thus a rule that the $\mathrm{pH}$ maximum of the enzyme activity is evaluated as most appropriate for the substrate and inhibitor determination. And there is agreement that the $\mathrm{pH}$-dependence of the observed inhibiting effect often corresponds to that of the response of a biosensor [37-38].

It is for this reason that the operation of the biosensor was evaluated at different $\mathrm{pH}$ values. Other researchers [39-42] have shown that the optimal working $\mathrm{pH}$ for the cholinesterases is near 7.5 but it depends on the polymer matrix used for enzyme immobilisation, although working $\mathrm{pH}$ values between 8 and 9 have also been reported [30]. In [Fig-3] the results for the investigation into the effect of different $\mathrm{pH}$ values on the working of the Au/MBT/PANI/AChE/ PVAc biosensor is displayed.

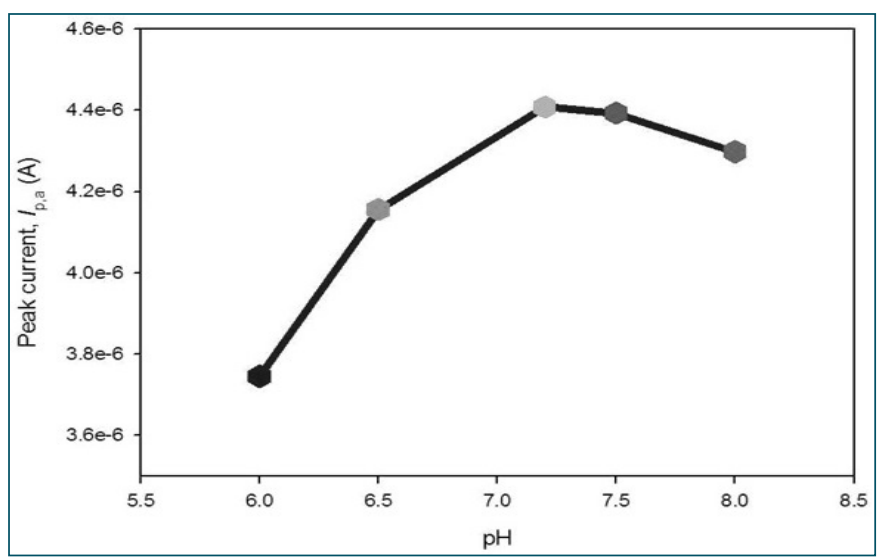

Fig. 3- Graph displaying the effect of $\mathrm{pH}$ on the Au/MBT/PANI/ AChE/PVAc biosensor in $0.1 \mathrm{M}$ phosphate buffer, $\mathrm{KCl}(\mathrm{pH} 7.2)$ solution with $2 \mathrm{mM}$ of ATCh added

The Au/MBT/PANI/AChE/PVAc biosensor was evaluated at $\mathrm{pH}$ values of $6.0 ; 6.5 ; 7.2 ; 7.5$ and 8.0 in a $2 \mathrm{ml}$ of $0.1 \mathrm{M}$ phosphate buffer ( $\mathrm{pH} 7.2$ ) solution, to which a total of $2 \mathrm{mM}$ of ATCh substrate was added. The results obtained are shown in [Fig-3] indicating that the highest anodic current was obtained at $\mathrm{pH}=7.2$, while the result for $\mathrm{pH}=7.5$ is not far off. The response profile thus indicate that an optimum $\mathrm{pH}$ can be obtained between 7.0 and 7.5 , which falls within the range reported in literature [43-44] for the optimum $\mathrm{pH}$ of the free enzyme activity in solution. The results further illustrates that enzyme incorporated in the Au/MBT/PANI/AChE/PVAc biosensor, was easily accessed by the buffer solution and the acetylthiocholine used as substrate in the buffer solution.

\section{Stability Studies}

The first stability test performed with the constructed biosensor was a temperature stability study. It is a critical factor in the determination of the activity and stability of a biosensor, providing useful operational information $[38,43,45]$. The response of the Au/MBT/PANI/ AChE/PVAc biosensor to successive additions of the substrate ATCh in a $2 \mathrm{ml}$ of $0.1 \mathrm{M}$ phosphate buffer, $\mathrm{KCl}(\mathrm{pH} \mathrm{7.2)} \mathrm{solution,}$ was determined at different temperatures varying from 10 to $35^{\circ} \mathrm{C}$. In [Table-2] the results obtained for the response of the enzyme AChE at different temperatures are shown.

Table 2- Characteristics of the peak current results obtained for the stability tests performed on the Au/MBT/PANI/AChE/PVAc biosensor at different temperatures and after several days of operation, $0.1 \mathrm{M}$ phosphate buffer, $\mathrm{KCl}(\mathrm{pH} 7.2)$ solution $(n=2)$

\begin{tabular}{|lccc}
$\begin{array}{l}\text { Temperature } \\
\left({ }^{\circ} \mathbf{C}\right)\end{array}$ & $\begin{array}{c}\text { Results for Stability Testing of thick-film Biosensor } \\
\text { Anodic peak current } \\
\text { response, } I_{\mathrm{p}, \mathrm{a}}(\mathbf{A})\end{array}$ & $\begin{array}{c}\text { Days of Operation } \\
\text { Anodic peak current } \\
\text { response, } \mathbf{I}_{\mathrm{p}, \mathrm{a}}(\mathbf{A})\end{array}$ \\
\hline 10 & $5.385 \times 10^{-6}$ & 0 & $6.534 \times 10^{-6}$ \\
15 & $5.405 \times 10^{-6}$ & 7 & $6.246 \times 10^{-6}$ \\
20 & $5.175 \times 10^{-6}$ & 14 & $5.594 \times 10^{-6}$ \\
25 & $6.234 \times 10^{-6}$ & 21 & $5.485 \times 10^{-6}$ \\
30 & $4.028 \times 10^{-6}$ & 28 & $3.524 \times 10^{-6}$ \\
35 & $5.748 \times 10^{-6}$ & 35 & $2.925 \times 10^{-6}$ \\
\hline
\end{tabular}

The results shown in [Table-2] indicate that the activity of the immobilised enzyme reached a maximum at $25^{\circ} \mathrm{C}$, with the highest current obtained at this temperature. Investigation of the biosensor activity at low temperatures of 10,15 and $20^{\circ} \mathrm{C}$, it was observed that the activity of the enzyme was relatively similar. On the other hand, the higher temperatures of 30 and $35^{\circ} \mathrm{C}$ gave mixed results with the activity of the enzyme at average around $35^{\circ} \mathrm{C}$, while the lowest activity was obtained at $30^{\circ} \mathrm{C}$

The above results were further used to determine the long-term stability of the biosensor over 35 days. The Au/MBT/PANI/AChE/ PVAc biosensor was prepared under optimum conditions and stored at $4^{\circ} \mathrm{C}$ for a length of approximately 30 days and the biosensor was tested every 7 days by adding the substrate ATCh to a $2 \mathrm{ml}$ of $0.1 \mathrm{M}$ phosphate buffer, $\mathrm{KCl}(\mathrm{pH} 7.2)$ solution containing the biosensor, and measuring the current at every addition. The results obtained for the maximum current response after addition of the substrate to the biosensor on $0,7,14,21,28$ and 35 days are displayed in [Table-2].

The results in [Table-2] shows that a gradual decrease in maximum current response was observed over the 35 days of operation, with a bigger decrease in peak current observed after the $28^{\text {th }}$ day of biosensor operation. In the work done by Sen, et al. [43] a polyvinylferrocenium modified Pt electrode was constructed and the amperometric response of the biosensor to choline and acetylcholinesterase was measured, indicating that the enzyme electrode responses gradually decreased in the first 25 days. Therefore, it can be concluded that favourable long-term stability results were obtained for thick-film biosensor constructed in this study.

\section{Inhibition Studies for Standard Samples}

Inhibition plots for each of the carbamate pesticides investigated were obtained using the percentage inhibition method. In the inhibition method the biosensor was first placed in a stirred $1.0 \mathrm{ml}$ of 0.1 $\mathrm{M}$ phosphate $(0.1 \mathrm{M} \mathrm{KCl}, \mathrm{pH} 7.2)$ solution (anaerobic conditions) and multiple additions of a standard acetylthiocholine (ATCh) substrate solution was added until a stable current at a maximum concentration of $2.4 \mathrm{mM}$ was obtained. This steady state current is related to the activity of the enzyme in the biosensor when no inhibitor was present [30-33] 
After incubation of the biosensor in anaerobic conditions for $20 \mathrm{~min}$ with a standard pesticide saline acetone-phosphate buffer mixture, multiple additions of the standard ATCh substrate solution, to a fresh $1.0 \mathrm{ml}$ of $0.1 \mathrm{M}$ phosphate $(0.1 \mathrm{M} \mathrm{KCl}, \mathrm{pH} 7.2)$ solution (anaerobic conditions) and multiple additions of a standard acetylthiocholine (ATCh) substrate solution was again added. This was repeated until a stable current was obtained at a maximum concentration of $2.4 \mathrm{mM}$ of acetylthiocholine (ATCh). The percentage inhibition was then calculated for each of the pesticides evaluated. In [Table-3] the results calculated for the percentage inhibition of the AChE enzyme after incubation in pesticide solutions are shown [29].

Table 3- Table of results for the percentage inhibition results obtained at the six different carbamate pesticide concentrations investigated with the Au/MBT/PANI/AChE/PVAc biosensor

\begin{tabular}{|lcccc|}
\multicolumn{5}{c|}{ Biosensor Inhibition Results } \\
[pesticide], ppb -log [pesticide] \% I (dioxacarb) $\%$ I (aldicarb) & $\%$ I (carbofuran) \\
\hline 0.6 & 0.222 & 9.89 & 22.09 & 37.85 \\
1 & 0 & 14.53 & 30.63 & 42.13 \\
2 & -0.301 & 23.52 & 40.71 & 52.44 \\
5 & -0.699 & 36.58 & 54.67 & 65.53 \\
7 & -0.845 & 43.47 & 61.18 & 71.04 \\
10 & -1 & 49.82 & 69.35 & 75.62 \\
\hline
\end{tabular}

The Au/MBT/PANI/AChE/PVAc biosensor results shown in [Table3] indicate that an increase in the percentage inhibition was observed as the concentration of the standard pesticide solutions were increased. For the lowest concentration of $0.6 \mathrm{ppb}$ used, the results showed the lowest percentage inhibition with the highest percentage inhibition obtained when a concentration of $10 \mathrm{ppb}$ was investigated. The results in [Table-3] were plotted as graphs of percentage inhibition vs. - - og [pesticide] as shown in [Fig-4].

[Fig-4] shows the results for the combined plots for the percentage inhibition vs. -log [pesticide] for three different carbamate standard pesticide solutions investigated. The results for dioxacarb, aldicarb and carbofuran are shown in [Fig-4], indicating that the highest inhibition was obtained for carbofuran and the lowest for dioxacarb. Futher analysis of the percentage inhibition results shows that for dioxacarb, the pesticide biosensor achieved percentage inhibitions ranging from approximately 10 to $50 \%$ over pesticide concentrations ranging from 0.6 to $10.0 \mathrm{ppb}$. In the case of aldicarb, the percentage inhibitions ranged between approximately 22 to $69 \%$, while for carbofuran it ranged between approximately 38 to $76 \%$ over the same concentration range.

The results in [Table-3] and [Fig-4] were further used to determine the detection limit results that are shown in [Table-4].

The results in [Table-4] shows the values for the different parameters calculated from the inhibition plots of the Au/MBT/PANI/AChE/
PVAc biosensor results shown in [Fig-4].

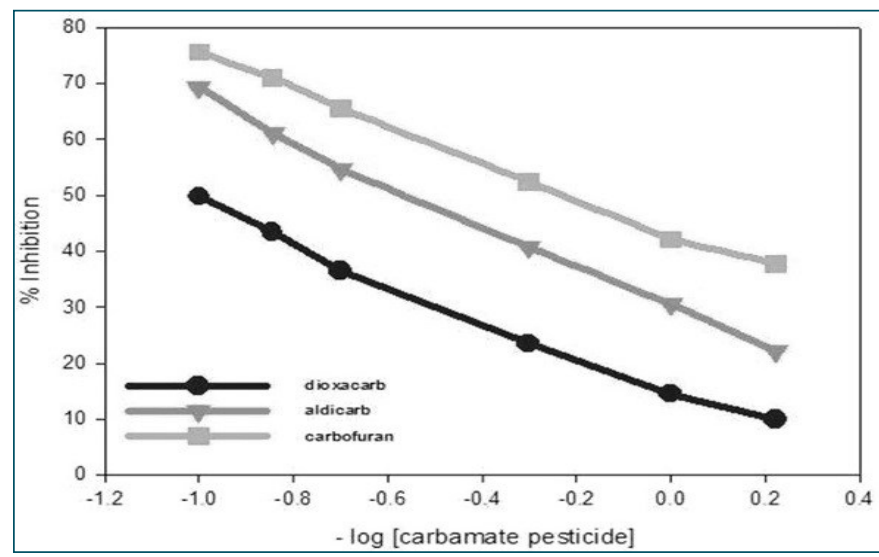

Fig. 4- Graph of percentage inhibition vs. -log [pesticide] results for three different carbamate pesticides investigated with the Au/MBT/ PANI/AChE/PVAc thick-film biosensor

Table 4- Results for the different parameters calculated from the inhibition plots of the Au/MBT/PANI/AChE/PVAc biosensor detection of standard carbamate pesticide solutions $(n=2)$

\begin{tabular}{|lccc|}
\multicolumn{3}{c}{ Detection Limit Results for Carbamate Pesticide Detection } \\
Pesticide & Sensitivity (\%I/decade) & Detection Limit (nM) Regression Coefficient \\
\hline dioxacarb & -38.11 & 1.572 & 0.99 \\
aldicarb & -36.15 & 1.209 & 0.995 \\
carbofuran & -34.21 & 0.249 & 0.996 \\
\hline
\end{tabular}

The data for the sensitivity and the detection limits of dioxacarb, aldicarb and carbofuran analysis were estimated from the inhibition plots. Analysis of the pesticide data shows that no results for the sensitivity were higher than two orders in comparison of the results for dioxacarb, aldicarb and carbofuran. Furthermore, although no big difference in the sensitivity for the individual pesticides were observed, carbofuran as pesticide delivered the highest inhibition results [Fig-4] and the lowest detection limit of $0.249 \mathrm{nM}$.

Analysis and comparison of the detection limits obtained in this study (results in [Table-4]) to that of other AChE enzyme inhibitionbased biosensor systems for pesticides are shown in [Table-5].

The results in [Table-5] are that obtained for the amperometric detection of the carbamate pesticide compounds listed.

It was found that the detection limit for carbofuran compared favourably with the results obtained for other biosensors constructed by various researchers. It was also observed that the Au/MBT/PANI/ AChE/PVAc biosensor constructed in this study offered a reasonable linear range for the carbamate pesticides determined and the detection limit was lower than some of those reported in literature [Table-5].

Table 5- Results for the comparison of present work with other AChE enzyme inhibition-based biosensor systems for the determination of carbamate pesticide compounds

\begin{tabular}{|c|c|c|c|c|c|}
\hline Pesticide Compound (s) & Immobilisation Matrix & Sample & Linear range & Detection Limit (LOD) & Reference \\
\hline \multirow{3}{*}{$\begin{array}{l}\text { Carbofuran; paraoxon } \\
\text { carbofuran; aldicarb; carbaryl } \\
\text { carbofuran }\end{array}$} & Entrapment in a PVA-SbQ polymer & Spiked river water samples & $3.0 \times 10^{-7}$ to $9.1 \times 10^{-8} \mathrm{M}$ & $3.0 \times 10^{-7} \mathrm{M}$ & [46] \\
\hline & Cross-linking with $\mathrm{GA}$ & Standard solutions & $0.2-166 \mathrm{ppb}$ & $0.2 \mathrm{ppb}$ & [47] \\
\hline & Cross-linking with AuNPs & Standard solutions & $0.2-100 \mathrm{nM}$ & $0.1 \mathrm{nM}$ & [48] \\
\hline \multirow{5}{*}{$\begin{array}{l}\text { carbofuran } \\
\text { carbofuran } \\
\text { carbofurana; } \\
\text { aldicarbb; } \\
\text { dioxacarbc }\end{array}$} & AChE-ChO bi-enzyme in PAMAM & Standard solutions & $0.05-0.09 \mathrm{nM}$ & $0.04 \mathrm{nM}$ & {$[48]$} \\
\hline & Entrapment in Nafion/BSA & Standard solutions & $0.1-100 \mathrm{nM}$ & $0.49 \mathrm{nM}$ & [48] \\
\hline & & & $0.25-2.83 \mathrm{nMa}$ & $0.249 \mathrm{nMa}^{2}$ & \\
\hline & Entrapment in MBT/PANI/PVAc & Standard solutions & $0.26-3.0 \mathrm{nM}^{\mathrm{b}}$ & $1.209 \mathrm{nM}^{\mathrm{b}}$ & This work \\
\hline & & & $0.28-3.45 \mathrm{nM}^{\mathrm{c}}$ & $1.572 \mathrm{nMc}^{\mathrm{c}}$ & \\
\hline
\end{tabular}




\section{Influence of Organic Solvents on Biosensor Response}

The detection of pesticides is generally performed in aqueous solution, but pesticide compounds are generally characterised by a low solubility in water and a high solubility in organic solvents. The activity and specificity of an enzyme is affected by the presence of organic solvents and it can induce extensive changes. Enzymes have further evolved to maintain their structural stability in aqueous medium, but organic solvents are known to disrupt the forces of interaction in the enzyme, causing changes in the kinetic and thermodynamic behaviour of the enzyme. If any changes occur in solvent hydrophobicity, dielectric constant and water content of the reaction medium, it will affect the ability of the enzymes to use their free energy of binding with a substrate, leading to changes in substrate specificity and reactivity.

Solvent platforms used for biosensing purposes can be classified into two groups, i.e. anhydrous organic media and water-containing media. One is anhydrous organic media that refers to pure solvents or a mixture of pure organic solvents that may be polar or non-polar in nature. Secondly, water-containing organic media consist of micro-aqueous systems, water-organic solvent mixtures, water and immiscible organic solvent biphasic systems and reverse micellar solutions [24,49-50].

Enzymes generally require some essential water of hydration for its activity and it is essential that non-polar solvents be saturated with water before they are used as reaction media for biosensing. In the case of polar organic solvents, they can be used as systems that contain some amount of water. The hydration of polar solvents ensures that the flexibility, structure and local dielectric constant of the enzyme redox site environment, stay as much as possible, unaltered $[24,29,32,40,52-54]$.

Therefore, to study the behaviour of the AChE enzyme in the thickfilm biosensor constructed in this study, it was decided to employ aqueous- polar solvent mixtures during inhibition studies. This allowed high solubility of the pesticide in the polar organic solvent, while the presence of water favoured the catalytic functioning of the enzyme. The study further investigated the use of $5 \%, 10 \%$ and no water in the aqueous- polar solvent mixtures employed in the investigation. The results obtained for the percentage inhibition studies of the enzyme AChE in the different aqueous- polar solvent mixtures investigated, are shown in [Table-6].

Table 6- Summary of the results obtained for the percentage inhibition of the enzyme AChE in the different polar aqueous-solvent mixtures investigated

\begin{tabular}{|c|c|c|c|c|}
\hline \multirow{2}{*}{$\begin{array}{l}\text { Polar } \\
\text { Organic } \\
\text { Solvent }\end{array}$} & \multirow{2}{*}{$\log P$} & \multicolumn{3}{|c|}{$\begin{array}{c}\% \text { Inhibition of Enzyme, AChE, in Different Solvent } \\
\text { Mixtures }\end{array}$} \\
\hline & & $\begin{array}{l}90 \% \text { aqueous- } \\
\text { solvent mixture }\end{array}$ & $\begin{array}{l}95 \% \text { aqueous- } \\
\text { solvent mixture }\end{array}$ & $\begin{array}{c}100 \% \text { pure } \\
\text { solvent }\end{array}$ \\
\hline cetonitrile & -0.33 & 41 & 63 & 93 \\
\hline acetone & -0.23 & 10 & 47 & 96 \\
\hline ethanol & -0.24 & 18 & 33 & 77 \\
\hline
\end{tabular}

The results in [Table-6] indicate that a $90 \%$ aqueous-solvent mixture of acetone and water gave the best results and the smallest degree of inhibition of the electrocatalytic effect of AChE in the Au/ MBT/PANI/AChE/PVAc biosensor investigated. The results obtained for the $95 \%$ aqueous-solvent mixtures and the pure polar organic solvents clearly indicate the solvent hydrating effect of the three solvent investigated increases as the amount of water is decreased. These results are in line with the investigations reported by Evtugyn, et al. [37] on the presence of water and in the enzyme's active centre, playing an important role in the functioning of the enzyme.

Similarly, Amine, et al. [46] have also reported that the nature and amount of organic solvent employed can strongly inactivate an enzyme's catalytic activity when inhibition experiments are performed in organic phase media. Furthermore, not only does the organic solvent influence the enzyme's performance, but the configuration used in the biosensor design is another important factor.

\section{Conclusion}

An AChE biosensor based on the immobilisation of the enzyme in a PANI/PVAc polymer matrix on an Au/MBT modified electrode was developed for the determination of nanoMolar concentrations of carbofuran, aldicarb and dioxacarb carbamate pesticide solutions. The biosensor constructed in this study offered a reasonable linear range between 0.25 to $3.0 \mathrm{nM}$ for the detection of carbofuran, aldicarb and dioxacarb and the detection limit was lower than some of those reported in literature. The detection limits for the individual carbamate pesticides were $0.249 \mathrm{nM}$ for carbofuran, followed by $1.209 \mathrm{nM}$ for aldicarb and $1.572 \mathrm{nM}$ for dioxacarb. It was further shown that the constructed biosensor can operate in aqueousorganic solvent mixtures of acetonitrile, acetone and ethanol, confirming that the presence of water in the enzyme's active centre plays an important role in the catalytic activity of the enzyme. This organic phase sensor will be applied to various agricultural products such as vegetables and fruits in the near future for carbamate and organophosphate pesticide detection.

\section{Acknowledgements}

The authors wish to express their gratitude to the National Research Foundation (NRF), South Africa and the Chemistry Department at the University of the Western Cape (UWC) for financial support, as well as the Department of Agriculture in Stellenbosch, for the initial supply of some pesticide standards. The assistance of the researchers in the SensorLab, Chemistry Department, UWC are also greatly acknowledged.

\section{References}

[1] Schulze H., Scherbaum E., Anastassiades M., Vorlova S., Schmid R.D. and Bachmann T.T. (2002) Biosensors and Bioelectronics, 17, 1095-1105.

[2] Dutta K., Bhattacharyay D., Mukherjee A., Setford S.J., Turner A.P.F. and Sarkar P. (2008) Ecotoxicology and Environmental Safety, 69, 556-561.

[3] Somerset V., Baker P. and Iwuoha E. (2009) Journal of Environmental Science and Health, B44, 164-178.

[4] De Albuquerque Y.D.T. and Ferreira L.F. (2007) Analytica Chimica. Acta., 596, 210-221.

[5] Karousos N.G., Aouabdi S., Way A.S. and Reddya S.M. (2002) Analytica Chimica. Acta., 469, 189-196.

[6] Pandey P.C., Upadhyay S., Pathak H.C., Pandey C.M.D. and Tiwari I. (2000) Sensors and Actuators B., 62, 109-116.

[7] Pogacnik L. and Franko M. (2003) Biosensors and Bioelectronics, 18, 1-9.

[8] Cheng X., Wang Q., Zhang S., Zhang W., He P. and Fang Y. (2007) Talanta, 71, 1083-1087.

[9] Manisankar P., Sundari P.L.A., Sasikumar R. and Palaniappan S.P. (2008) Talanta, 76, 1022-1028. 
[10]Hildebrandt A., Bragos R., Lacorte S. and Marty J.L. (2008) Sensors and Actuators B., 133, 195-201.

[11]Du D., Chen W., Cai J., Zhang J., Qu F. and Li H. (2008) Journal of Electroanalytical Chemistry, 623, 81-85.

[12]Abad J.M., Pariente F., Hernandez L., Abruna H.D. and Lorenzo E. (1998) Analytical Chemistry, 70, 2848-2855.

[13]Suwansa-ard S., Kanatharana P., Asawatreratanakul P., Limsakul C., Wongkittisuksa B. and Thavarungkul P. (2005) Biosensors and Bioelectronics, 21, 445-454.

[14]Mulchandani A., Chen W., Mulchandani P., Wang J. and Rogers K.R. (2001) Biosensors and Bioelectronics, 16, 225-230.

[15]Lee J.H., Park J.Y., Min K., Cha H.J., Choi S.S. and Yoo Y.J. (2010) Biosensors and Bioelectronics, 25, 1566-1570.

[16]Somerset V.S., Klink M.J., Baker P.G.L. and Iwuoha E.I. (2007) Journal of Environmental Science and Health, B42, 297-304.

[17]Somerset V.S., Klink M.J., Sekota M.M.C., Baker P.G.L. and Iwuoha E.I. (2006) Analytical Letters, 39, 1683-1698.

[18]Morrin A., Moutloali R.M., Killard A.J., Smyth M.R., Darkwa J. and Iwuoha E.I. (2004) Talanta, 64, 30-38.

[19]Raj C.R. and Ohsaka T. (2003) Journal of Electroanalytical Chemistry, 540, 69-77.

[20]Michira I., Akinyeye R., Somerset V., Klink M.J., Sekota M., AlAhmed A., Baker P.G.L. and Iwuoha E. (2007) Macromolecular Symposia, 255, 57-69.

[21]Mazur M., Tagowska M., Pays B. and Jackowska K. (2003) Electrochemistry Communications, 5, 403-407.

[22]Mathebe N.G.R., Morrin A. and Iwuoha E.I. (2004) Talanta, 64, 115-120.

[23]Mazur M. and Krysinski P. (2001) Electrochimica Acta., 46, 3963-3971.

[24]Iwuoha E.I., De Villaverde D.S., Garcia N.P., Smyth M.R. and Pingarron J.M. (1997) Biosensors and Bioelectronics, 12, 749761.

[25]Joshi K.A., Tang J., Haddon R., Wang J., Chen W. and Mulchandania A. (2005) Electroanalysis, 17, 54-58.

[26]Sotiropoulou S., Fournier D. and Chaniotakisa N.A. (2005) Biosensors and Bioelectronics, 20, 2347-2352.

[27]Pritchard J., Law K., Vakurov A., Millner P. and Higson S.P.J. (2004) Biosensors and Bioelectronics, 20, 765-772.

[28]Iwuoha E.I. and Smyth M.R. (2003) Biosensors and Bioelectronics, 18, 237-244.

[29]Somerset V.S. (2007) Mercaptobenzothiazole-on-gold biosensor systems for organophosphate and carbamate pesticide sompounds., PhD Dissertation, University of the Western Cape.

[30]Albareda-Sirvent M., Merkoci A. and Alegret S. (2001) Analytica Chimica Acta, 442, 35-44.

[31]Sotiropoulou S. and Chaniotakis N.A. (2005) Analytica Chimica Acta, 530, 199-204.

[32]Wilkins E., Carter M., Voss J. and Ivnitski D. (2000) Electrochemistry Communications, 2, 786-790.

[33]Caetano J. and Machado S.A.S. (2008) Sensors and Actuators B., $129,40-46$.

[34]Nunes G.S., Barcelo D., Grabaric B.S., Diaz-Cruz J.M. and Ribeiro M.L. (1999) Analytica Chimica Acta., 399, 37-49.
[35]Ricci F., Amine A., Palleschi G. and Moscone D. (2003) Biosensors and Bioelectronics, 18, 165-174.

[36]Kuralay F., Ozyoruk H. and Yildiz A. (2005) Sensors and Actuators B., 109, 194-199.

[37]Evtugyn G.A., Budnikov H.C. and Nikolskaya E.B. (1998) Talanta, 46, 465-484.

[38]Bucur B., Danet A.F. and Marty J.L. (2005) Analytica Chimica Acta., 530, 1-6.

[39]Yang M., Yang Y., Yang Y., Shen G. and Yu R. (2005) Analytica Chimica Acta., 530, 205-211.

[40]Palchetti I., Cagninia A., Del Carlo M., Coppi C., Mascini M. and Turner A.P.F. (1997) Analytica Chimica Acta., 337, 311-321.

[41]Hart A.L., Collier W.A. and Janssen D. (1997) Biosensors and Bioelectronics, 12, 645-654.

[42]Cagnini A., Palchetti I., Lionti I., Mascini M. and Turner A.P.F. (1995) Sensors and Actuators B., 24-25, 85-89.

[43]Sen S., Gulce A. and Gulce H. (2004) Biosensors and Bioelectronics, 19, 1261-1268.

[44]Arkhypova V.N., Dzyadevych S.V., Soldatkin A.P., Elukaya A.V., Martelet C. and Jaffrezic-Renault N. (2003) Biosensors and Bioelectronics, 18, 1047-1053.

[45]Timur S., Pazarlioglu N., Pilloton R. and Telefoncu A. (2004) Sensors and Actuators B., 97, 132-136.

[46]Amine A., Mohammadi H., Bourais I. and Palleschi G. (2006) Biosensors and Bioelectronics, 21, 1405-1423.

[47]Nunes G.S., Jeanty G. and Marty J.L. (2004) Analytica Chimica Acta., 523, 107-115.

[48]Yin H., Ai A., Xu J., Shi W. and Zhu L. (2009) Journal of Electroanalytical Chemistry, 637, 21-27.

[49]Chatterjee S. and Russell A.J. (1992) Biotechnology and Bioengineering, 40(9), 1069-1077.

[50]Dordick J.S. (1992) Biotechnology Progress, 8, 259-267.

[51]Borzeix F., Monot F. and Vandecasteele J.P. (1992) Enzyme and Microbial Technology, 14(10), 791-797.

[52]Klibanov A.M. (2003) Current Opinion in Biotechnology, 14, 427 -431 .

[53]Andreescu S., Noguer T., Magearu V. and Marty J.L. (2002) Talanta, 57, 169-176.

[54]Iwuoha E.I., Adeyoju O., Dempsey E., Smyth M.R., Liu J. and Wang J. (1995) Biosensors and Bioelectronics, 10, 661-667. 